\title{
Jet mixing when heating oil and fuel oil in storage tanks
}

\author{
J. V. Karaeva ${ }^{1}$, V. O. Zdor ${ }^{1, *}, A . I . \mathrm{Kadyirov}^{1}$, and E. V. Shamsutdinov ${ }^{2}$ \\ ${ }^{1}$ Kazan Scientific Center of the Russian Academy of Sciences, Kazan, Russia \\ ${ }^{2}$ Kazan State Power Engineering University, Kazan, Russia
}

\begin{abstract}
This paper presents the research results of jet mixing and heating processes of crude oil of the Zachebashskoe field (Republic of Tatarstan) and fuel oil M100 in a tank with a capacity of $2000 \mathrm{~m}^{3}$. Circulation systems with nozzle inclination in the range from $-25^{\circ}$ up to $125^{\circ}$ are considered. The presence and washing out of bottom sediments in the tank are modeled. The time required for removing the bottom sediments and for heating the tank to the optimum temperature is determined. The best heating for the tank with oil and fuel oil was observed at the nozzle inclination in the range from $-25^{\circ}$ up to $60^{\circ}$. The optimal nozzle inclination was $115^{\circ}$ for washing out the bottom sediments in the oil tank. To remove sediment in a tank with fuel oil it is recommended to use the same nozzle inclinations as for heating.
\end{abstract}

\section{Introduction}

Bottom sediments are formed when storing oil and oil products in tanks. Their presence leads to a decrease in tank capacity, accelerates corrosion processes, increases the time of technological operations, blocks the discharge lines of tanks, and also has a toxic influence on maintenance staff [1]. The devices that prevent the deposition of bottom sediments without stopping the tank operation are of particular interest [2]. Also, cold climatic conditions make it necessary to heat such tanks. Paper [3] notes that in China, the heating mode of tanks for crude oil by spraying the hot oil through nozzles is widely used in recent years.

Jet mixers are cheap and compared to the mechanical mixers can be easily installed. Only a pump and nozzle are needed to organize the circulation mixing. Installation of such a mixing system is simple [4]. It should be noted that at jet mixing, there are less dead zones in the tank, especially concerning the storage tanks of rectangular shape and small size [5]. Sometimes at circulation mixing, it is necessary to increase the jet velocity only by $20 \%$ to completely remove sediment in the oil tank [6].

Jet mixing is widely used in tanks to deal with various bottom sediments [7-10].

The literature most widely presents the research results of mass transfer processes at jet mixing of various liquids [11-14].

The aim of this work is a numerical study of jet mixing and heating processes in a high capacity tank. It will allow determining the time required for removing bottom sediments as well as the heating of the tank up to the optimum temperature.

\section{Mathematical model}

The mathematical model is developed under the following assumptions:

- the hydrodynamic mode of fluid circulation in the tank is assumed to be laminar with a given profile of the velocity vector at the tank inlet;

- the medium under consideration (oil and oil products) is a viscous fluid with a density and coefficient of effective viscosity depending on temperature;

- rheological behavior of the medium is Newtonian;

- circulation heating process and the mixing process are non-stationary;

- gravity forces are volume forces influencing the heating process of the fluid;

- the average concentration during mixing is constant.

In this work, we use a mathematical model that is based on the fundamental system of differential equations of energy conservation and continuum mechanics - equations of motion and continuity:

$$
\frac{d V}{d t}=\frac{1}{\rho} \operatorname{div} \sigma
$$

where $\sigma-$ stress tensor,

$$
\begin{gathered}
\operatorname{div} \vec{V}=0 \\
\rho c_{p} \frac{d T}{d t}=\operatorname{div}(\lambda \operatorname{grad} \sigma) \\
\frac{\partial \alpha}{\partial t}+\bar{V} \cdot \nabla \alpha=0
\end{gathered}
$$

\footnotetext{
* Corresponding author: zdor_victoria@mail.ru
} 
At $t=0, \bar{V}=0$ the initial hydrodynamic conditions are as follows.

Boundary conditions for the velocity are the following:

- at the solid boundaries of the tank, the no-slip conditions of the fluid are set;

- at the inlet openings, velocity profiles corresponding to the formed velocity profile of Newtonian fluid in a round pipe are set;

- at the outlet, the condition for velocity stabilization is set.

The volume average temperature of oil in the tank at the start of heating is $288 \mathrm{~K}$, and fuel oil M100 is $303 \mathrm{~K}$.

Boundary conditions for temperature are the following:

- at the solid and open boundaries, as well as at the outlet of the tank, boundary conditions of the second kind - heat insulation - are set;

- at the inlet, the temperature of "hot" oil (oil product) supplied to the tank is set.

The initial distribution of volume concentration (condition of the presence of bottom sediments) can be written in the form of the following function $[15,16]$ :

$$
\alpha_{0}=\alpha_{\max } \frac{\pi / 2-\operatorname{arctg}\left(b\left(z-h_{0}\right)\right)}{\pi / 2+\operatorname{arctg}\left(b h_{0}\right)}
$$

where $b$ - some parameter, the value of which determines the approximation width of the sediment layer height $h_{0}$; $\alpha_{\max }$ - the maximum possible volumetric concentration of the dispersed phase.

The sediment height is taken $1 \mathrm{~m}$ from [17].

Boundary conditions for concentration are the following:

- at the solid and open boundaries of the tank is applied the following $\frac{\partial \alpha}{\partial n}=0$, where $n$ - the normal to the solid and open boundaries;

- at the inlet $\alpha=$ const;

- at the outlet, the condition for stabilization of concentration fields is set.

The modeling of mixing and heating processes of crude oil of the Zachebashskoye field (Republic of Tatarstan) and fuel oil M100 is performed.

Experimental studies of the oil rheological properties were carried out on a Physica MCR 102 rheometer using coaxial cylinders measuring system (SS27). Temperature control was carried out using Peltier elements with an accuracy of up to $0.01 \mathrm{~K}$. The obtained experimental data were approximated by the E.C. Andrade equation [18].

$$
\mu(T)_{o i l}=0.0728 \cdot e^{-0.034 \cdot(T-273)} R^{2}=0.9941
$$

Oil density $\rho_{\text {oil }}[19]$ was:

$$
\rho_{\text {oil }}=877 /(1+0.000807(T-293))
$$

Oil thermal conductivity $\lambda_{\text {oil }}[19]$ was:

$$
\lambda_{\text {oil }}=\frac{0.1175}{d_{15}^{15}}(1.1472-0.00054 \cdot T)
$$

Oil heat capacity $c_{p(\text { oil })}$ [19] was:

$$
c_{p(o i l)}=\frac{4187}{\sqrt{d_{15}^{15}}}(0.403+0.000405 \cdot T)
$$

The fuel oil viscosity $\mu_{\text {fuel oil }}$ was obtained by the Walther formula [20]:

$$
\begin{aligned}
& \mu_{\text {fuel oil }}=\left[\operatorname { e x p } _ { 1 0 } \left(\exp _{10}[9,855\right.\right. \\
& -3,745 \lg (T+273)])-0,8] \cdot 10^{-6} \cdot \rho_{\text {fuel oil }}
\end{aligned}
$$

where fuel oil density $\rho_{\text {fuel oil }}$ [20] was:

$$
\rho_{\text {fuel oil }}=881-3.04(T-341)
$$

Fuel oil heat capacity $c_{p}^{\text {fuel oil }}$ [20] was:

$$
c_{p}^{\text {fuel oil }}=1736.4+2.51 \cdot(T-273) .(10
$$

Fuel oil thermal conductivity $\lambda_{\text {fuel oil }}$ [20] was:

$$
\lambda_{\text {fuel oil }}=0.158-0.0002093 \cdot(T-293) .
$$

Numerical studies were performed in COMSOL Multiphysics $3.5 \mathrm{a}$. Verification of the model and the solution method is presented in $[16,21]$.

\section{Results and discussion}

The PBC 2000 tank (vertical steel tank) was considered. The diameter of the tank was $15.5 \mathrm{~m}$ the height was 12 $\mathrm{m}$. The diameter of the supply manifold was $7.67 \mathrm{~m}$. It was located at a height of $0.275 \mathrm{~m}$ above the tank bottom. The diameter of the supply nozzle was $0.12 \mathrm{~m}$ the nozzle angle $\theta$ varied from -25 to 125 degrees (relative to the tank bottom). At $\theta=0^{\circ}$, the nozzle was parallel to the tank bottom the flow was directed towards the wall. The diameter of the outlet connection was 0.1 $\mathrm{m}$ it was located in the center of the tank bottom.

The behavior of heat and mass transfer was determined by the distribution of the velocity vector field in the tank. During jet mixing and heating, the circulation currents appeared. Numerical studies were performed at $\mathrm{Re}=288$. Figures 1 and 2 show the streamlines distribution in the considered tanks at $\theta=15^{\circ}$, $75^{\circ}$ and $125^{\circ}$. 


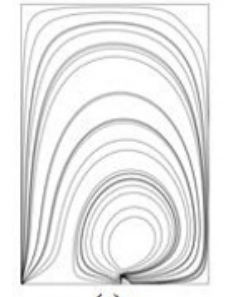

(a)

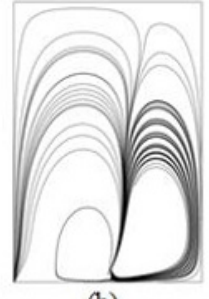

(b)

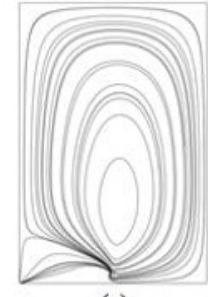

(c)

Fig. 1. Streamlines in the tank with oil: a) $\theta=15^{\circ}$; b) $\theta=75^{\circ}$; c) $\theta=125^{\circ}$.

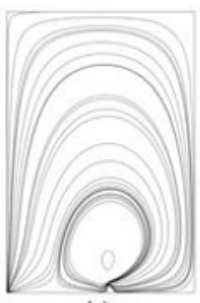

(a)

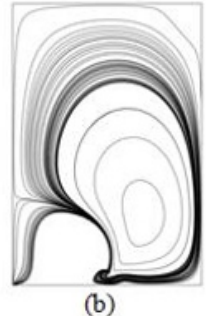

(b)

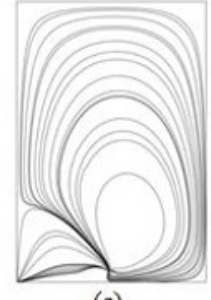

(c)

Fig. 2. Streamlines in the tank with fuel oil: a) $\theta=15^{\circ}$; b) $\theta=75^{\circ}$; c) $\theta=125^{\circ}$.

The streamlines at $\theta=15^{\circ}$ and $\theta=125^{\circ}$ are the same for fuel oil and oil. However, at $\theta=75^{\circ}$ they differ; two zones of fluid circulation are observed for oil.

Based on the calculated hydrodynamic fields in COMSOL Multiphysics, the volume of "mixing zones" in the tank was determined. Let us consider the function:

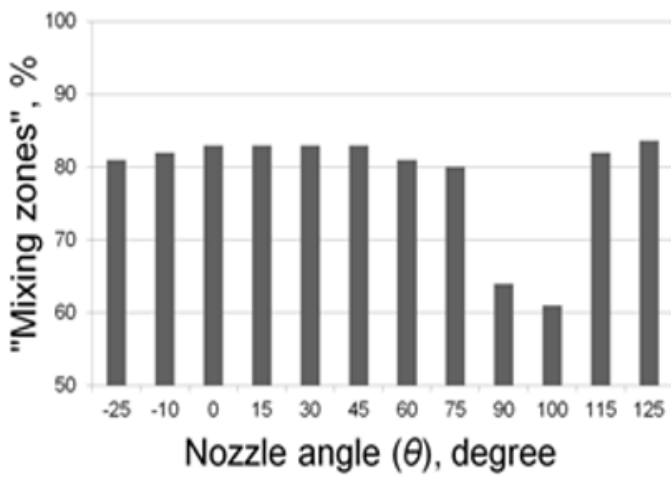

(a)

$$
f(v) \approx \begin{cases}1, & \text { at } v>v_{0} \\ 0, & \text { at } v<v_{0}\end{cases}
$$

where $v_{0}$ - velocity in stagnant zones (less than $5 \%$ of the average velocity value) then the volume of "mixing zones" was calculated as

$$
\mathrm{W}_{\text {mixing }}=\iiint_{V} f(v) d v
$$

The following function was used as $f(v)$ :

$$
f(v)=1-\frac{\pi / 2-\operatorname{arctg}\left[b\left(v-v_{0}\right)\right]}{\pi / 2+\operatorname{arctg}\left(b \cdot v_{0}\right)}, b=10^{9}
$$

Figure 3 shows the volume of "mixing zones" in the PBC 2000 tank. For the tank with oil, the smallest share of "mixing zones" was $61 \%$, and the nozzle angle was $75^{\circ}$. When mixing fuel oil, the smallest "mixing zones" were observed at $\theta=90^{\circ}(64 \%)$ and $\theta=100^{\circ}(61 \%)$. This occurs because "hot" jet leaving the nozzle collides with a cold oil layer and is divided into two circulation flows. The formed circulation zones are smaller; in addition, the velocity in them is also lower.

Figures 4 and 5 show the removal of bottom sediments in the tank. Sediment height was $1 \mathrm{~m}$. In the tank with fuel oil, the best removal of bottom sediments was observed after two hours.

Numerical studies were performed for the Reynolds number $\operatorname{Re}=288$, at that the viscosity of the fluids under

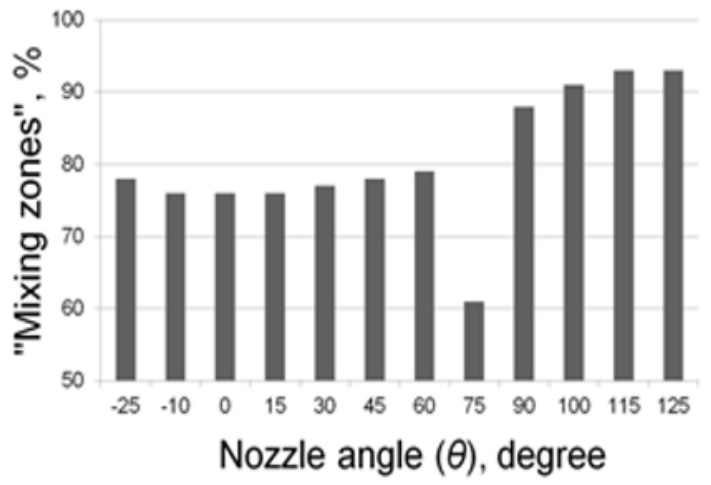

(b)

Fig. 3. Volume of «mixing zones» in the tank.

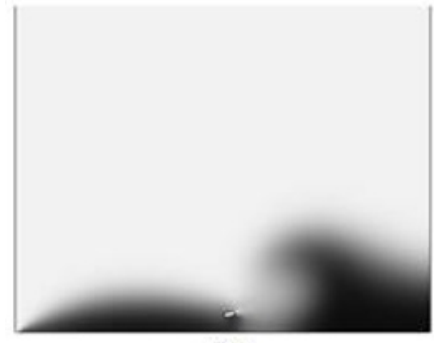

(a)

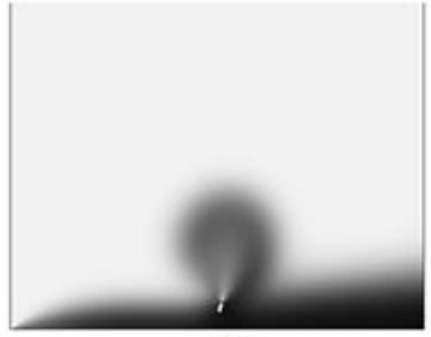

(b)

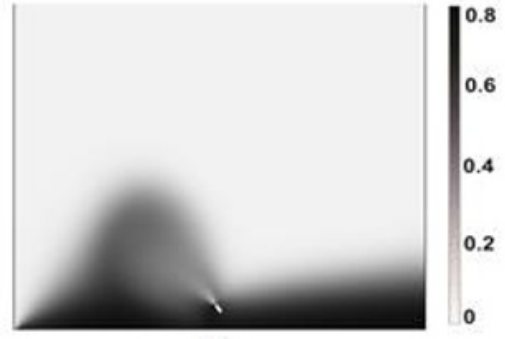

(c)

Fig. 4. Washing out of bottom sediments in the tank with oil (after 2 hours): a) $\theta=15^{\circ}$; b) $\theta=75^{\circ}$; c) $\theta=125^{\circ}$. 


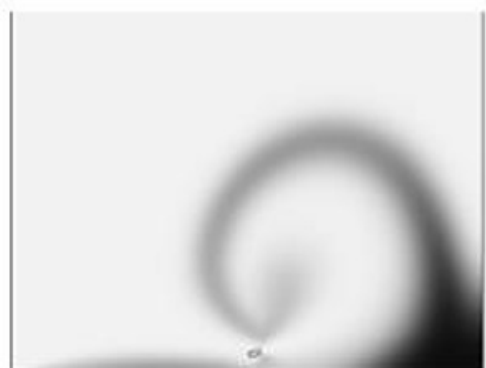

(a)

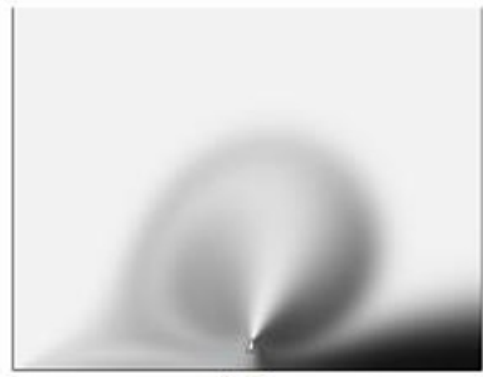

(b)

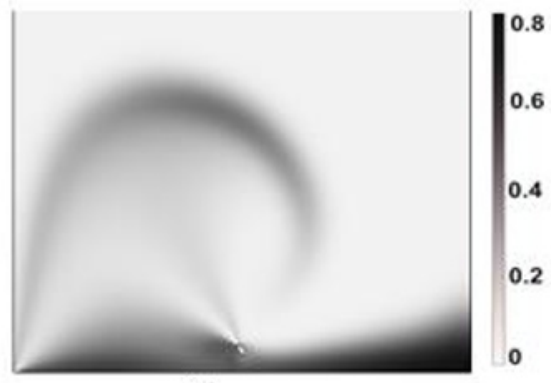

(c)

Fig. 5. Washing out of bottom sediments in the tank with fuel oil (after 2 hours): (a) $\theta=15^{\circ}$; (b) $\theta=75^{\circ}$; (c) $\theta=125^{\circ}$.

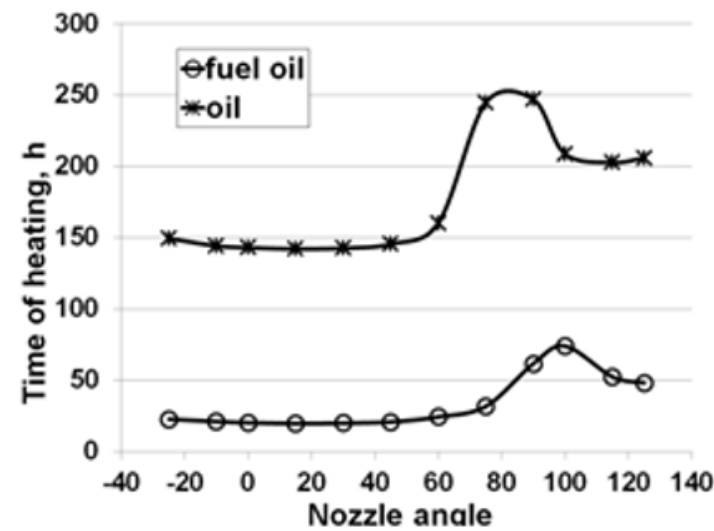

(a)

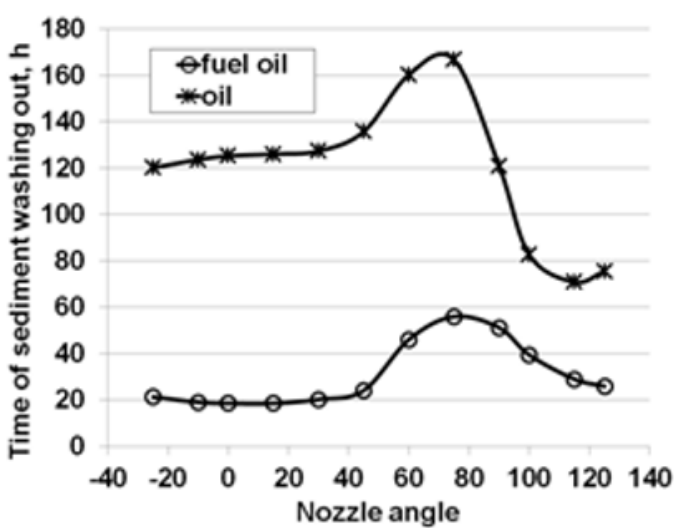

(b)

Fig. 6. The time required for (a) removal of bottom sediments in the tank; (b) tank heating.

consideration differs significantly, therefore, the average velocity in the tank with oil is lower and the sediment washing out is slower.

Figure 6 shows the dependencies of time of the heating and washing out of sediment on the nozzle angle.

The fastest washing out of bottom sediments in the tank with oil can be carried out when using the nozzle with the angle $\theta=115^{\circ}$. The time spent on this technological operation can be reduced by 2 times compared to standard nozzles. When removing sediment in the tank with fuel oil, the optimal nozzle angle is in the range from $-25^{\circ}$ up to $45^{\circ}$ at that the operating time spent by the circulation system will be 20 hours.

The optimal nozzle angle is from $-25^{\circ}$ to $60^{\circ}$ with an operating time of circulation heating of 147 hours to warm the tank with oil up to $313 \mathrm{~K}$.

The average time of heating the tank with fuel oil to $333 \mathrm{~K}$ was 21 hours, the nozzle angle varied from $-25^{\circ}$ to $60^{\circ}$.

\section{Conclusions}

The following was obtained in the course of mathematical modeling of jet mixing and heating processes of oil and fuel oil in the storage tank. The optimal nozzle angle for heating oil and fuel oil in a $2000 \mathrm{~m} 3$ tank falls in the range from $-25^{\circ}$ to $60^{\circ}$. In the tank with fuel oil, these geometrical characteristics of the nozzle arrangement provide effective washing out of bottom sediments. The recommended nozzle angle is $115^{\circ}$ to remove sediment in the tank with oil. Thus, for oil, it is necessary to vary the nozzle angle for effective washing out of bottom sediments or heating.

The reported study was funded by RFBR, project number 18-31-20037.

\section{References}

[1] M. Hassanzadeh, L. Tayebi, H. Dezfouli, Investigation of factors affecting on viscosity reduction of sludge from Iranian crude oil storage tanks Petroleum Science 15, 634-43 (2018)

[2] V.G. Butov, A.V. Nikulchikov, V.K. Nikulchikou, V.A. Solonenko, A.A. Yashchuk, Vimulation study of bottom sediments jet erosion in oil tank. Bulletin of the Tomsk Polytechnic University-Geo Assets Engineering 329, 93-100 (2018)

[3] J. Zhao, L.X. Wei, H. Dong, F.R. Liu, Research on heat transfer characteristic for hot oil spraying heating process in crude oil tank Case Studies in Thermal Engineering 7, 109-19 (2016)

[4] M. Rahimi, A. Parvareh, CFD study on mixing by coupled jet-impeller mixers in a large crude oil storage tank Computers \& Chemical Engineering 31, 737-44 (2007)

[5] A.A.L. Neyestanak, G. Asadi, S. Daneshmand, Introducing new relation to estimate 
mixing time of crude oil tank having submerged rotary jet mixer. Revue Roumaine De Chimie 61, 67-74 (2016)

[6] H. Barekatain, S.H. Hashemabadi, Improving of Mixing by Submerged Rotary Jet (SRJ) System in a Large Industrial Storage Tank by CFD Techniques. In: International Conference on Numerical Analysis and Applied Mathematics (ICNAAM), Halkidiki, (2011)

[7] A. Maleki, S. Hormozi, Submerged jet shearing of visco-plastic sludge Journal of Non-Newtonian Fluid Mechanics 252, 19-27 (2018)

[8] B. Ali, Performance of a hydraulic jet agitation system with different jet nozzle sizes in the sprayer. TANK Scientific Papers-Series a-Agronomy 60, 449-54 (2017)

[9] J.A. Bamberger, C.W. Enderlin, Asme Experimental evaluation of dual-opposed jet mixer pump performance for slurry mixing. Proceedings of the Asme Fluids Engineering Division Summer Meeting, 2, (2016)

[10] Bhattacharjee P.K., Kennedy S., Eshtiaghi N., Parthasarathy R., Flow regimes in the mixing of municipal sludge simulant using submerged, recirculating jets Chemical Engineering Journal 276, 137-44 (2015)

[11] P. Manjula, P. Kalaichelvi, C. Shanawaskhan, K. Dheenathayalan, Effect of radial angle on mixing time for a double jet mixer Asia-Pacific Journal of Chemical Engineering 5, 544-51 (2010)

[12] E. Bumrungthaichaichan, A. Namkanisorn, S. Wattananusorn, CFD modelling of pump-around jet mixing tanks: a discrepancy in concentration profiles Journal of the Chinese Institute of Engineers 41, 61221(2018)

[13] T. Jorakit, N. Phaiboonsilpa, A. Namkanisorn, P. Ponpo, E. Bumrungthaichaichan, S. Wattananusorn, Influence of jet discharge velocity profile on CFD simulation of pump-around jet mixing tank. In: MATEC Web of Conferences (2018)

[14] E. Bumrungthaichaichan, S. Wattananusorn, CFD modeling of pump-around jet mixing tanks: a reliable model for overall mixing time prediction Journal of the Chinese Institute of Engineers 42 (2019)

[15] J.V. Karaeva, G.R. Khalitova, Evaluation of mixing quality in anaerobic digester Journal of Renewable and Sustainable Energy 7 (2015)

[16] J.V. Karaeva, G.R. Khalitova, D.A. Kovalev, I.A. Trakhunova, Study of the process of hydraulic mixing in anaerobic digester of biogas plant. Chemical and Process Engineering-Inzynieria Chemiczna I Procesowa 36, 101-12 (2015)

[17] Kh.A. Allam, W.F. Bakr, Assessment of the Exposure Dose During Removal of TENORM Sludge from Crude Oil Storage Tanks Arab Journal of Nuclear Sciences and Applications 46, 90-93 (2015)

[18] E. Andrade, Viscosity of Liquids Nature 125, 309-324 (1930)

[19] A.V. Moiseev, Calculation methods for determining the physicochemical properties of hydrocarbon systems, oils and petroleum products: Examples and tasks: textbook. allowance Komsomolskon-Amur (GOUVPO KnAGTU) 179 (2010)

[20] Yu.G. Nazmeev, Fuel oil facilities TPP Moscow ( MPEI) 612 (2002)
[21] V.O. Zdor, R.F. Kamalov, J.V. Karaeva, A.I. Kadyirov, Investigation of circulating heating of mazut. Transactions of Academenergo 1, $42-49$ (2018) 